\title{
Estudo sobre a rentabilidade da cultura da soja em propriedades rurais de Diamantino/MT
}

\begin{abstract}
Cleiton Franco
Mestrado em Economia pela Universidade Federal de Mato Grosso - UFMT Professor do Departamento de Ciências Contábeis da Universidade do Estado de Mato Grosso - UNEMAT Avenida dos Ingás, 3001. Jardim Imperial. Sinop/MT. CEP: 78550-000

E-mail: cleitonfranco@unemat.br

André da Silva Matheus Universidade do Estado de Mato Grosso - UNEMAT

E-mail: andrematheus@hotmail.com

Karine Medeiros Anunciatto Universidade do Estado de Mato Grosso - UNEMAT

E-mail:karine@unemat.br

Talitha Soyara Zanini Mestrado em Ambiente e Sistemas de Produção Agrícola pela Universidade do Estado de Mato Grosso - UNEMAT Professora pela Secretaria de Estado de Educação - SEDUC/MT E-mail: talisoyara@hotmail.com
\end{abstract}

\section{RESUMO}

A gestão da rentabilidade é fundamental para o sucesso produtivo da atividade agrícola de curto prazo. Diante disso, o objetivo deste estudo foi analisar a rentabilidade comparativa da cultura da soja aplicada a propriedades rurais situadas no município de Diamantino, Mato Grosso. Utilizou-se o método de custeio variável para três períodos distintos referentes às safras 2007/2008, 2008/2009 e 2009/2010. Os resultados encontrados apontam que os custos são afetados devido à oscilação de preços de sementes e defensivos, identifica que a produtividade é fator determinante na geração de receita, que a oscilação de preços de mercado afeta a comercialização e, consequentemente, os resultados operacionais das empresas agrícolas que produzem soja no município.

Palavras-chave: Rentabilidade da cultura da soja. Custeio variável. Mato Grosso. 


\section{ABSTRACT}

The profitability management is critical to the success of productive agricultural activity short term. The aim of this study was to analyze the comparative profitability of soybean applied to farms located in Diamantino, Mato Grosso. We used the variable costing method for three different periods related crops 2007/2008, 2008/2009 and 2009/2010. The results show that the costs are affected due to fluctuating prices of seeds and pesticides. It also identifies that productivity is an important factor in generating revenue to defray production. We conclude that the price fluctuation of the market affects the market and therefore the operating results of agricultural enterprises that produce soybeans in the city.

Keywords: Profitability of soybean. Variable costs. Mato Grosso.

\section{INTRODUÇÃO}

Mato Grosso é um estado internalizado, conhecido como primeiro produtor e exportador da produção agrícola de variedades de soja convencional e transgênica em todo território brasileiro. Nessas três décadas muito se avançou em pesquisa, tecnologia, descoberta de novas variedades e conquista de novos mercados.

A cultura da soja emprega cerca de 300 mil pessoas na produção e industrialização e responde por $\mathrm{R} \$ 11$ bilhões do Valor Bruto da Produção (VBP). De acordo com a Associação dos Produtores de Soja e Milho do Estado (APROSOJA, 2010), em 10 anos o PIB da soja vai dobrar, elevando ainda mais o Índice de Desenvolvimento Humano (IDH) dos municípios, fomentando a economia, gerando empregos e atraindo indústrias.

Em levantamento realizado pelo Instituto Matogrossense de Economia Agropecuária (IMEA), há evidencias de que a área de soja explorada por grandes grupos dobrou em Mato Grosso nos últimos cinco anos, demonstrando que os 20 maiores grupos plantaram 1,228 milhão de hectares na safra 2009/2010 e responderam por $20 \%$ dos 6,217 milhões de hectares cultivados com a oleaginosa no estado (APROSOJA, 2010; IMEA, 2010). 
Em função do potencial agrícola do Mato Grosso, empresas produtoras nacionais de carnes instalaram-se no estado, assim como em Goiás, em busca de insumos baratos para a produção de carnes (SILVA; ONOYAMA, 2008). No caso da carne bovina, as grandes áreas de terras permitem a criação extensiva, e mais recentemente aponta-se intenções de confinameto, ampliando a produção pecuária. No caso dos frangos e suínos há a integração da produção com as grandes áreas que desenvolvem o plantio de soja e milho, principais componentes da ração animal. O clima favorece ambas as culturas, milho e soja, criando condições favoráveis que, junto com os preços da terra, reduzem os custos de produção destes insumos (FRANCO, 2009).

A disponibilidade de insumos foi o motivador do movimento de instalação das plantas industriais da Sadia e Perdigão em MT (FRANCO, 2009). Soja e milho ocupam lugar de destaque na agricultura do estado. Estes são os principais insumos utilizados na produção de frangos de corte. A disponibilidade doméstica, dependência de recursos externos e preços dos insumos podem demonstrar o potencial competitivo do estado.

A literatura contábil a respeito da análise de custeio variável associado à rentabilidade de custos de produção demonstra que a utilização desse custeio proporciona uma análise satisfatória propiciando uma melhor tomada de decisão acerca da rentabilidade em empresas agropecuárias (MALAVAZI; FUGITA; ROSA, 2006; ANDRADE et al., 2012). Este método para a cultura da soja também é bastante relacionado quando se compara a rentabilidade das variedades de soja convencional e transgênica, demonstrando vantagens comparativas na produção da soja transgênica (MENEGATTI; BARROS, 2008; FRANCO et al., 2011) Na pecuária também se utiliza tal metodologia de forma comparativa dos métodos de custeio por absorção e variável na análise de viabilidade de produção (EYERKAUFER; COSTA; FARIA, 2007; CELESTINO; SILVEIRA, 2009). O presente estudo se assemelha aos demais no sentido de utilizar o custeio por absorção, porém se diferencia quanto à análise comparativa entre duas propriedades rurais e entre períodos, evidenciando a evolução dos custos de produção e volatilidade de preços de mercado. 
A produção de soja de Mato Grosso destaca-se por sua importância no cenário mundial. O objetivo deste estudo é, portanto, analisar a rentabilidade dos custos de produção em propriedades rurais de produção agrícola de soja situadas no município de Diamantino, Mato Grosso, considerando três períodos. Para tal, faz-se uso do método denominado custeio variável e ferramentas de análise de custo, volume e lucro, a fim de obter controle preciso e possibilitar um planejamento adequado a atividade agrícola para gestão de resultados.

\section{REFERENCIAL TEÓRICO}

A Contabilidade de Custos possui papel relevante ao coletar, processar e informar de que maneira os recursos aplicados no sistema produtivo de bens ou serviços afetam os resultados de uma empresa. As empresas classificam os custos em fixos e variáveis, e esses têm como base seu comportamento de acordo com a mudança no volume de produção. (LEONE, 1991; MARTINS, 2001; PADOVEZE, 2000; ATKINSON et al., 2000; HANSEN; MOWEN, 2001)

Os custos fixos são definidos como inalteráveis, independentemente das variações das atividades ou das vendas. De certa maneira, apesar de fixos, sofrem variações devido a inflação ou volatilidade de preços. Os custos fixos são tipos específicos de custos que em determinado período de tempo e considerando a capacidade de produção ou instalação, haverão de existir, independente do volume de atividade ou oscilação da produção na empresa (BRUNI; FAMÁ, 2004; MARION, 2002).

Os custos variáveis são tipos de custos que apresentam variação na proporção das variações ocorridas do volume de produção ou outra medida de atividade (BRUNI; FAMÁ, 2004). Quanto maior a quantidade produzida, maior o seu consumo. Define-se então como conceito de custos variáveis, aqueles que, em função do valor total, tenderão a variar proporcionalmente à quantidade produzida, enquanto, o custo por unidade permanece inalterado. De outra forma, os custos fixos totais, diante dos limites da capacidade instalada, permanecem constantes diante de oscilações no volume de 
produção, mas o custo por unidade varia de forma inversamente proporcional à quantidade produzida (MARTINS, 2001; MEGLIORINI, 2007).

Os métodos de custeio são fontes gerenciais que auxiliam as empresas na tomada de decisão com maior eficiência e qualidade, realizando transações de negócios e obtendo resultados operacionais positivos objetivando o lucro. O método de custeio é o procedimento no qual os custos são apropriados aos seus produtos finais. Koliver (2003) caracteriza os sistemas de custeio, fazendo o reconhecimento necessário dos seus comportamentos diante da variação no grau de ocupação da entidade, referindo-se à separação dos custos fixos e variáveis.

Neste sentido, apresenta-se o custeio variável como base fundamental na apropriação de todos os custos variáveis - diretos e indiretos - aos produtos finais, relacionados ao grau de ocupação da empresa. Custeio variável é o método de custeio em que todos os custos variáveis de fabricação ou produção são considerados custos inventariáveis ou identificáveis (HORNGREN; FOSTER; GEORGE, 1987; GARRISON; NOREEN; BREWER, 2007). Desta forma, excluem-se dos custos inventariáveis, todos os custos fixos de fabricação ou produção, tornando-os custos do período (LOPES DE SÁ, 1990).

\section{PROCEDIMENTOS METODOLÓGICOS}

Quanto à natureza, a pesquisa realizada se caracteriza como aplicada, uma vez que se destinou a atender ao objetivo de analisar a rentabilidade dos custos de produção em propriedades rurais de produção agrícola de soja situadas no município de Diamantino/MT. Quanto à abordagem do problema a pesquisa é quantitativa, pois foram desenvolvidos cálculos necessários à apuração dos dados para a análise da rentabilidade dos custos de produção (GIL, 2003). A pesquisa atende, também, ao método comparativo, na medida em que o estudo desenvolveu-se em duas fazendas do município cujos resultados obtidos foram comparados. 
Os custos de produção coletados foram separados em fixos e variáveis, de ambas as propriedades rurais, Fazenda Santa Rita e AGL situadas no município, utilizando-se o método de custeio variável, considerando o período safra de produção de soja de junho a março, evidenciando as evoluções dos insumos agrícolas nos três períodos de safra: 2007/2008, 2008/2009 e 2009/2010. São apresentados os custos totais de produção referentes aos três períodos de safras, observando-se a quantidade de hectares e detalhando a participação dos insumos em relação ao custo total. A comparabilidade dos três períodos e utilização de duas propriedades valida a situação de estudo, evidenciando não somente a evolução dos custos fixos e variáveis, bem como as características de duas propriedades que produzem a mesma cultura.

\subsection{Margem de Contribuição}

Margem de Contribuição corresponde à diferença entre o preço de venda e o custo variável que resta para cobrir os custos fixos e obtenção de lucros para a empresa como resultado (PADOVEZE, 2000; GARRISON; NOREEN; BREWER, 2007;). Através do cálculo da $\mathrm{MC}$ de cada produto, o administrador financeiro poderá analisar a viabilidade de produção.

$\mathrm{MCu}=\mathrm{PVu}-\mathrm{Cvu}$

\subsection{Ponto de Equilíbrio}

Ponto de equilíbrio representa a quantidade de venda necessária a ser realizada no período para a geração das receitas suficientes para custear o total dos custos variáveis gerados, inclusas todas as despesas comerciais geradas e despesas fixas que a empresa apresentar no período. Representa o resultado em que as receitas totais alcançam os custos totais. A partir daí, com uma unidade adicional de venda, a firma passa a evidenciar lucro (MARION, 2002; PADOVEZE, 2000; GARRISON; NOREEN; BREWER, 2007). O Ponto de Equilíbrio pode ser calculado por meio das quantidades ou na forma contábil (valor). 
Ponto de Equilíbrio Contábil ou em Valor:

$\mathrm{PE}$ valor $=\underline{\mathrm{CF}}$

$$
\% \mathrm{MC}
$$

Onde:

CF é o custo fixo total

\% MC são as receitas brutas menos os custos variáveis totais

Ponto de Equilíbrio em quantidades:

$\mathrm{PE}$ quantidade $=\underline{\mathrm{CF}}$

$$
\mathrm{P}-\mathrm{Cvu}
$$

Onde:

CF é o custo fixo total

CVu é o custo variável unitário

$\mathrm{P}$ é o preço de mercado do produto $(\mathrm{R} \$$ sacas $)$

\subsection{Margem de Segurança Operacional}

A margem de segurança operacional corresponde à quantidade de produtos ou de receitas operadas acima do ponto de equilíbrio (MEGLIORINI, 2007; BRUNI; FAMÁ, 2004). A margem de segurança corresponde ao volume de unidades vendidas deduzida a quantidade no ponto de equilíbrio. Quanto maior for a margem de segurança, maior a capacidade de geração de lucro e, também, maior a segurança de que a empresa não incorrerá em prejuízos.

\subsection{Alavancagem Operacional}

A alavancagem operacional decorre da existência de custos e despesas operacionais fixos que permanecem inalterados dentro de certos intervalos de flutuação de produção e vendas (BRAGA, 1995). Alavancagem operacional é obtida à medida em que a empresa aumenta sua produção ou receita sem alteração nos custos e despesas fixas, proporcionando um crescimento proporcional no lucro ao aumento custos e despesas variáveis (MEGLIORINI, 2007). 


\subsubsection{Grau de Alavancagem Operacional}

O grau de alavancagem operacional (GAO) é a medida dos efeitos provocados nos lucros pelas alterações ocorridas nas vendas (BRAGA, 1995; MEGLIORINI, 2007). È obtida pela razão da variação do percentual no lucro operacional e variação no percentual das vendas

$\mathrm{GAO}=\frac{\text { Variação Percentual no Lucro Operacional }}{\text { Variação Percentual nas Vendas }}$

\section{RESULTADOS E DISCUSSÃO}

Inicialmente são apresentados os custos e a descrição das propriedades. Em seguida são realizados os comparativos, para posteriormente fazer-se a aplicação da análise gerencial.

A Fazenda Santa Rita situa-se no município de Diamantino, na BR 364 no km 328, $40 \mathrm{~km}$ à direita, distrito do município de Deciolândia. Na propriedade são produzidas as culturas de soja e milho safrinha e pecuária bovina. A Fazenda tem uma área total de 4.970 hectares, incluindo reservas, pastagens e área de agricultura. A cultura de soja ocupa a maior parcela de área, totalizando 4.000 hectares, sendo 600 hectares de uma área arrendada nas divisas da Santa Rita. Na propriedade é produzida soja convencional.

No ano safra 2008/2009 houve um elevado aumento dos custos variáveis e fixos, os custos variáveis comparados com os da Safra 2007/2008 elevaram-se aproximadamente $22 \%$ tendo como fator de maior influência o aumento dos preços dos adubos e fertilizantes e despesas administrativas correspondentes ao pagamento de terceirização de colheita. Outro item que influenciou expressivamente foi o insumo sementes, afetado pelos elevados preços da soja neste período. 
Os custos fixos também responderam por aumento significativo referente a safra 2007/2008, tendo um aumento de $31 \%$ sido influenciado pelo crescente quadro de pessoal e salários de funcionários registrando 66\% com relação a safra 2007/2008. Outro item que influenciou o aumento dos custos fixos no ano safra 2008/2009 foram as despesas administrativas justificadas pelo fato da assessoria agronômica receber serviços em sacas de soja. Outro fator no período foi a apresentação de preços mais expressivos que o período safra 2007/2008.

No ano safra 2009/2010 os custos de produção foram menos expressivos que no período anterior, derivada da baixa especulação no mercado de adubos e defensivos e redução nos preços dos insumos sementes. Um dos itens que mais apresentaram aumento no ano safra $2009 / 2010$ foi os insumos defensivos, devido a problemas representados por pragas e nematóides, obrigando a utilização intensiva de produtos químicos e defensivos. O que se observa nestes três períodos é o aumento gradativo da manutenção das maquinas, evidenciando a depreciação das maquinas e implementos (Tabela 1). 
Estudo sobre a rentabilidade da cultura da soja em propriedades rurais de Diamantino/MT Cleiton Franco, André da Silva Matheus, Karine Medeiros Anunciatto, Talitha Soyara Zanini

Tabela 1 - Demonstrativo dos Custos Totais de Produção de Soja Referentes Safra 2007/2008, Safra 2008/2009 e Safra 2009/2010 na Fazenda Santa Rita - Método Custeio Variável

\begin{tabular}{|c|c|c|c|c|c|c|}
\hline \multirow{4}{*}{ Descrição } & \multicolumn{2}{|l|}{ Área Plantada - He 4.000} & \multicolumn{2}{|c|}{ Área Plantada - He 4.000} & \multicolumn{2}{|c|}{ Área Plantada - He 4.000} \\
\hline & \multicolumn{2}{|l|}{ Safra 2007/2008 } & \multicolumn{2}{|l|}{ Safra $2008 / 2009$} & \multicolumn{2}{|l|}{ Safra 2009/2010 } \\
\hline & Custo & Partic. & Custo & Partic. & Custo & Partic. \\
\hline & Total & $\%$ & Total & $\%$ & Total & $\%$ \\
\hline \multicolumn{7}{|l|}{ CUSTOS VARIÁVEIS } \\
\hline Sementes & $286.628,02$ & 7,50 & $449.237,37$ & 9,55 & $348.424,12$ & 7,90 \\
\hline Adubos e Fertilizantes & $947.144,49$ & 24,77 & $1.251 .276,58$ & 26,59 & $906.215,51$ & 20,56 \\
\hline Calcário & $66.242,15$ & 1,73 & $55.000,00$ & 1,17 & $60.000,00$ & 1,36 \\
\hline Defensivos químicos & $1.058 .275,90$ & 27,68 & $914.057,79$ & 19,43 & $1.306 .819,04$ & 29,64 \\
\hline Combustíveis & $253.725,69$ & 6,64 & $384.794,05$ & 8,18 & $310.727,65$ & 7,05 \\
\hline Manutenção de Máquinas & $336.467,86$ & 8,80 & $506.367,27$ & 10,76 & $515.883,88$ & 11,70 \\
\hline Fretes & $190.934,50$ & 4,99 & $61.735,00$ & 1,31 & $132.641,48$ & 3,01 \\
\hline Mão de Obra Variável & $67.697,85$ & 1,77 & $41.244,30$ & 0,88 & $80.801,47$ & 1,83 \\
\hline Despesas Administrativas & - & - & $233.878,82$ & 4,97 & $38.930,68$ & 0,88 \\
\hline Total Custo Variáveis & $3.207 .116,46$ & & $3.897 .591,18$ & & $3.700 .443,83$ & \\
\hline \multicolumn{7}{|l|}{ CUSTOS FIXOS } \\
\hline Mão de Obra - Fixa & $188.339,34$ & 4,93 & $313.568,68$ & 6,66 & $286.006,63$ & 6,49 \\
\hline Depreciações & $236.000,00$ & 6,17 & $236.000,00$ & 5,02 & $236.000,00$ & 5,35 \\
\hline Serviços Profissionais & $48.760,00$ & 1,28 & $63.000,00$ & 1,34 & $62.000,00$ & 1,41 \\
\hline Cantina & $23.738,89$ & 0,62 & $26.420,55$ & 0,56 & $28.772,95$ & 0,65 \\
\hline Despesas Administrativas & $8.340,00$ & 0,22 & $43.460,34$ & 0,92 & $9.008,91$ & 0,20 \\
\hline Outras despesas Fixas & $6.490,00$ & 0,17 & $5.480,00$ & 0,12 & $6.360,00$ & 0,14 \\
\hline Arrendamentos & $105.000,00$ & 2,75 & $120.000,00$ & 2,55 & $80.000,00$ & 1,81 \\
\hline Total Custos Fixos & $616.668,23$ & & $807.929,57$ & & $708.148,49$ & \\
\hline \multirow[t]{3}{*}{ Custo Total } & $3.823 .784,69$ & 100,00 & $4.705 .520,75$ & 100,00 & $4.408 .592,32$ & 100,00 \\
\hline & \multicolumn{2}{|l|}{ Safra 2007/2008 } & \multicolumn{2}{|l|}{ Safra 2008/2009 } & \multicolumn{2}{|l|}{ Safra $2009 / 2010$} \\
\hline & & 164.000 & & 160.000 & & 162.000 \\
\hline
\end{tabular}

A Fazenda AGL situa-se no município de Diamantino, na BR 364 no Km 328, 52 km à Direita, distrito de Deciolândia. Na propriedade são produzidas as culturas de soja e milho safrinha e gado. A Fazenda tem uma área total de 46.380 hectares, incluindo reservas, pastagens e área de agricultura. A cultura de soja ocupa uma área de 5.100 hectares, onde é produzida soja convencional. 
No ano safra 2008/2009 observa-se um elevado aumento dos custos variáveis e fixos. Comparativamente, os custos variáveis da Safra 2007/2008 aumentaram 31\%, influenciados pela elevação dos preços dos adubos e fertilizantes e sementes. Neste período houve também expressivo aumento nos gastos com defensivos devido a compras com compromisso de entrega de soja a base de troca pelos produtos, situação comum neste tipo de atividade, evidenciada por período com elevados preços de mercado.

Os custos fixos também apresentaram aumentos significativos referentes à safra $2007 / 2008$, revelando incremento de $30 \%$, influenciados pelo aumento nos gastos com mão-de-obra fixa. No ano safra $2009 / 2010$ os custos de produção foram reduzidos, comparativamente ao período anterior, resultante da baixa expectativa do mercado de adubos e defensivos e redução nos preços das sementes. $O$ que se observa para os três períodos é o aumento gradativo de gastos com a manutenção das máquinas, indicação da crescente depreciação da frota (Tabela 2). 
Tabela 2 - Demonstrativo dos Custos Totais de Produção de Soja Referente Safra 2007/2008, Safra 2008/2009 e Safra 2009/2010 na Fazenda AGL - Método Custeio Variável

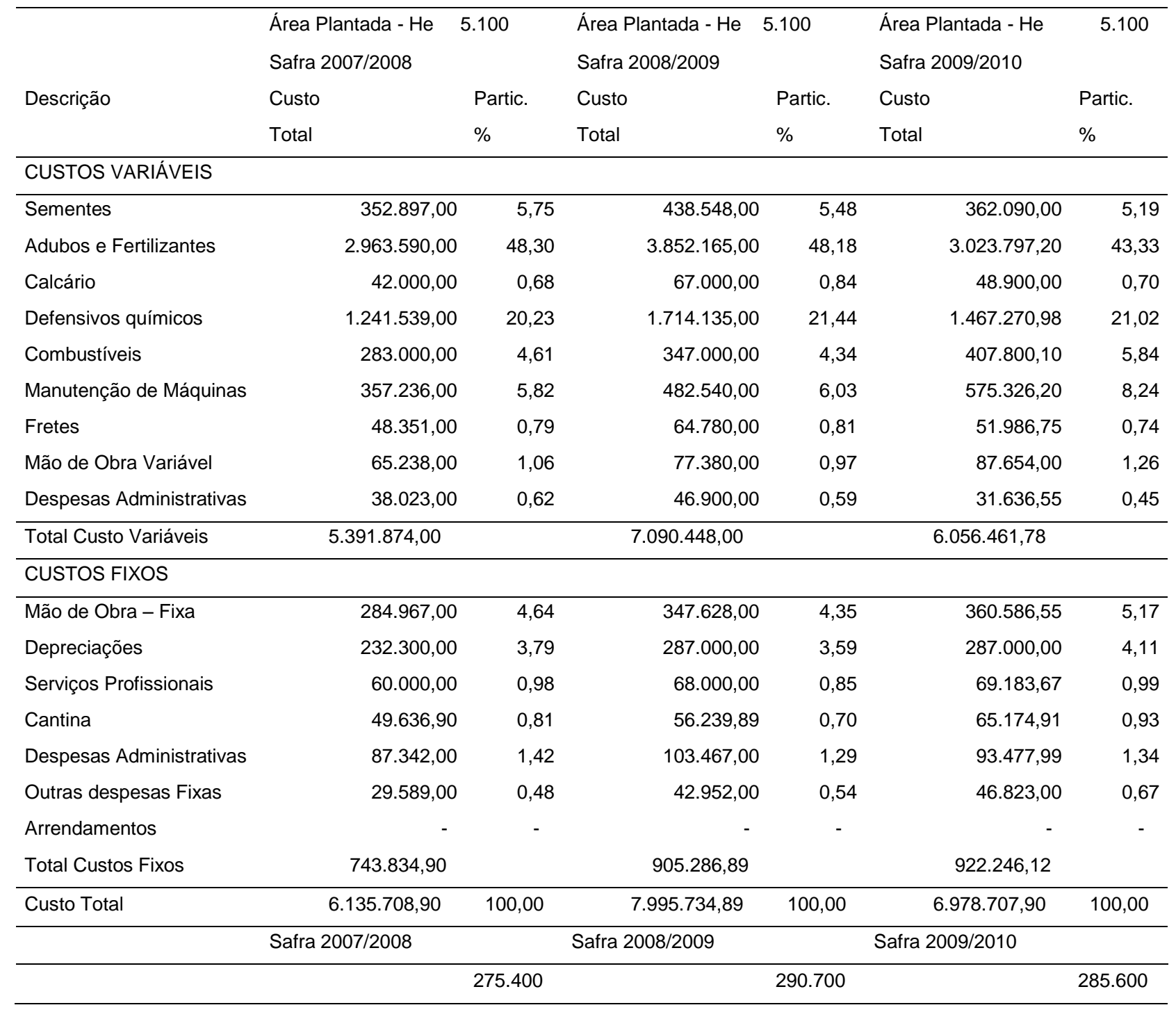

Comparando os dados dos custos totais apresentados, nota-se que a fazenda Santa Rita apresenta um custo de produção menor que a fazenda AGL, o que parece normal, uma vez que sua área de produção é menor. No ano safra 2007/2008 os custos variáveis de produção por hectare da Fazenda AGL foram $31,86 \%$ maiores que os da Fazenda Santa Rita, justificados pela diferença de investimentos em insumos, a exemplo de adubos e fertilizantes, onde a representação atingiu 54,96\% dos custos variáveis na fazenda AGL e 29,53\% dos custos variáveis na fazenda Santa Rita. 
Já os custos fixos da fazenda Santa Rita foram maiores que os da fazenda AGL por área em hectare, tendo a fazenda Santa Rita um custo fixo de 5,70\% a mais em relação a propriedade AGL. Com o insumo defensivo a fazenda Santa Rita apresentou investimento $10 \%$ superior a AGL. Nota-se que os investimos por hectare produzido da Fazenda Santa Rita são maiores que o da propriedade AGL, apresentando diferença somente nos insumos adubos onde a AGL aplicou $86,12 \%$ a mais que a Santa Rita.

Na safra 2008/2009 na fazenda AGL também há um custo variável maior que o da Santa Rita na ordem de 42,68\%, decorrente dos mesmos fatores da safra 2007/2008 onde os investimentos em adubos e fertilizantes foram maiores que os da Santa Rita. $O$ destaque novamente deve-se aos itens adubos e fertilizantes, apresentando maior índice de diferença, assim como na safra $07 / 08$, onde a Santa Rita aplicou $32,10 \%$ dos custos variáveis e a $A G L 54,33 \%$. Já para os defensivos nesta safra não se observou grandes divergências de investimentos, contudo a propriedade Santa Rita continua a evidenciar os outros custos variáveis mais elevados que a AGL. Assim como na safra anterior, os custos fixos da fazenda Santa Rita foram mais elevados que a da AGL, representado $13,78 \%$ a mais de gastos.

Finalmente, na safra 2009/2010 repetem-se as diferenças nos anos anteriores onde a propriedade $A G L$ tem gastos mais elevados com custos variáveis, com diferença de aproximadamente $28,37 \%$ a maior em relação aos da Fazenda Santa Rita. O insumo com maior indicador de diferença, assim como na safra 08/09 continua relacionado com adubos e fertilizantes onde a Santa Rita aplicou $24,49 \%$ dos custos variáveis e a AGL 49,93\%; repetindo os índices da safra $07 / 08$ os investimentos em defensivos e químicos representaram 11,09\%, comparado com o da AGL. Contudo, a Santa Rita continua com os outros custos variáveis mais elevados que a AGL. Já nos custos fixos as duas fazendas tiveram praticamente os mesmos gastos com uma diferença de $1,68 \%$ a mais nos gastos da fazenda Santa Rita.

As diferenças nos gastos variáveis podem ser justificáveis e compreendidas quando comparadas com a produtividade das duas fazendas. Observa-se na safra 2007/2008 que a fazenda Santa Rita apresentou produtividade de 41 sacas por hectare 
enquanto a AGL 54 sacas por hectare, evidenciando diferença de produção de 31,77\%. As diferenças de produção acentuam-se na safra 2008/209 onde a santa Rita apresenta produtividade de 40 sacas por hectare comparada a propriedade AGL com 57 sacas por hectare, diferença de 42,50\%. Na safra 2009/2010 também há diferença, porém menor comparativamente ao período anterior, porém superior ao primeiro período, onde a produtividade da Santa Rita resulta em 40,5 sacas por hectare, enquanto a AGL apresenta 56 sacas por hectare, ou seja, uma diferença de 38,27\%.

Quanto aos custos fixos, examinando a safra de 07/08, nota-se que a Santa Rita tem um custo fixo de depreciação maior que a AGL. Os custos com mão-de-obra da Fazenda Santa Rita são menores em relação a AGL. Um ponto relevante é o Arrendamento, uma vez que a AGL não tem custos com arrendamento, explicando sua redução nos custos fixos de produção. Na safra 08/09 percebe-se pouca variação nos custos fixos, exceto em relação ao arrendamento da propriedade Santa Rita. Para a safra 09/10, assim com na safra anterior, não ocorreram variações relevantes na comparação das duas propriedades, novamente evidenciado o custo de arrendamento.

\subsection{Comparativo dos resultados das propriedades Santa Rita e AGL}

Nesta etapa são examinados os resultados da comercialização da produção das propriedades Fazenda Santa Rita e AGL, considerando as variáveis de venda, preço unitário, custo de produção, lucro bruto total, quantidade e lucro por hectare produzido. 
Estudo sobre a rentabilidade da cultura da soja em propriedades rurais de Diamantino/MT

Cleiton Franco, André da Silva Matheus, Karine Medeiros Anunciatto, Talitha Soyara Zanini

Tabela 3- Demonstração do Resultado do Exercício referente Safra 2007/2008, Safra 2008/2009 e Safra 2009/2010 da Fazenda Santa Rita

\begin{tabular}{lrrr}
\hline & SAFRA 2007/2008 & SAFRA 2008/2009 & SAFRA 2009/2010 \\
\hline 1 -VENDA DE SOJA EM SACAS & 164.000 & 160.000 & 162.000 \\
2 - PREÇO UNITARIO DE VENDA & 27,50 & 37,50 & 27,50 \\
3 -TOTAL VENDA DE SOJA = 1X2 & $4.510 .000,00$ & $6.000 .000,00$ & $4.455 .000,00$ \\
4 - CUSTO DE PRODUÇÃO & $3.823 .784,69$ & $4.705 .520,75$ & $4.408 .592,32$ \\
5 - LUCRO BRUTO TOTAL = 3-4 & $686.215,31$ & $1.294 .479,25$ & $46.407,68$ \\
6 - QUANTIDADE DE He PRODUZIDOS & $4.000,00$ & $4.000,00$ & $4.000,00$ \\
5 - LUCRO BRUTO POR He PRODUZIDO = 5/6 & $\mathbf{1 7 1 , 5 5}$ & $\mathbf{3 2 3 , 6 2}$ & $\mathbf{1 1 , 6 0}$ \\
\hline
\end{tabular}

Tabela 4- Demonstração do Resultado do Exercício referente Safra 2007/2008, Safra 2008/2009 e Safra 2009/2010 da Fazenda AGL

\begin{tabular}{lrrr}
\hline & SAFRA 2007/2008 & SAFRA 2008/2009 & \multicolumn{1}{c}{ SAFRA 2009/2010 } \\
\hline 1 -VENDA DE SOJA em sacas & 275.400 & 290.700 & 285.600 \\
2 - PREÇO UNITARIO DE VENDA & 27,50 & 37,50 & 27,50 \\
3 -TOTAL VENDA DE SOJA = 1X2 & $7.573 .500,00$ & $10.901 .250,00$ & $7.854 .000,00$ \\
4 - CUSTO DE PRODUÇÃO & $6.135 .708,90$ & $7.995 .734,89$ & $6.978 .707,90$ \\
5 - LUCRO BRUTO TOTAL = 3 - 4 & $1.437 .791,10$ & $2.905 .515,11$ & $875.292,10$ \\
6 - QUANTIDADE DE He PRODUZIDOS & $5.100,00$ & $5.100,00$ & $5.100,00$ \\
5 - LUCRO BRUTO POR He PRODUZIDO = 5/6 & $\mathbf{2 8 1 , 9 2}$ & $\mathbf{5 6 9 , 7 1}$ & $\mathbf{1 7 1 , 6 3}$ \\
\hline
\end{tabular}

Comparando o resultado dos exercícios das fazendas Santa Rita e AGL nota-se uma diferença expressiva no que se refere à rentabilidade. Mesmo com um custo de produção por hectare superior a propriedade Santa Rita nos três períodos analisados, a fazenda AGL obteve na safra 2007/2008 um lucro bruto $64,34 \%$ superior ao da Santa Rita; na safra 2008/2009 com um lucro bruto de 56,80\% a mais e na safra 2009/2010 com um lucro bruto de $1.479,57 \%$ a mais que a propriedade Santa Rita. Essas diferenças são justificadas pela produtividade das propriedades impulsionadas pelo preço de venda de mercado (Tabelas 3 e 4). 


\subsection{Análise gerencial nas propriedades Santa Rita e AGL}

Nesta etapa são analisadas a margem de contribuição, o ponto de equilíbrio, a margem de segurança operacional e o grau de alavancagem referente aos três períodos. A margem de contribuição serve para demonstrar quanto o produto contribui para pagamento dos custos fixos de produção.

Comparando as margens de contribuição das propriedades Santa Rita e AGL, tem-se os seguintes dados: na safra 2007/2008 e safra 2008/2009 a margem de contribuição das fazendas foram praticamente iguais, tendo diferença mais expressiva na safra 2009/2010 onde a Fazenda AGL obteve uma margem de contribuição 34,98\% maior que a Santa Rita (Tabelas 5 e 6).

Tabela 5- Margem de Contribuição referente Safra 2007/2008, Safra 2008/2009 e Safra 2009/2010 da Fazenda Santa Rita

\begin{tabular}{llll}
\hline Fazenda Santa Rita & SAFRA & SAFRA & SAFRA \\
& $2007 / 2008$ & $2008 / 2009$ & $2009 / 2010$ \\
\hline 1 - Produtividade em scs/há & 41,00 & 40,00 & 40,50 \\
2 - Custo Variável p/há & 801,78 & 974,40 & 925,11 \\
3 - Custos Fixos p/há & 154,17 & 201,98 & 177,04 \\
3 - Receita de Venda & 27,50 & 37,50 & 27,50 \\
4 - ( - ) Custos Variáveis p/ sc & 19,56 & 24,36 & 22,84 \\
5 - Margem de Contribuição p/sc = 3-4 & 7,94 & 13,14 & 4,66 \\
6 - ( - ) Custos Fixos p/ sc & 3,76 & 5,05 & 4,37 \\
7 - Lucro Líquido p/ sc = 5-6 & 4,18 & 8,09 & 0,29 \\
\hline
\end{tabular}


Estudo sobre a rentabilidade da cultura da soja em propriedades rurais de Diamantino/MT

Cleiton Franco, André da Silva Matheus, Karine Medeiros Anunciatto, Talitha Soyara Zanini

Tabela 6- Margem de Contribuição referente Safra 2007/2008, Safra 2008/2009 e Safra 2009/2010 da Fazenda AGL

\begin{tabular}{llll}
\hline Fazenda AGL & SAFRA & SAFRA & SAFRA \\
& $2007 / 2008$ & $2008 / 2009$ & $2009 / 2010$ \\
\hline 1 - Produtividade em sacas por hectare & 54,00 & 57,00 & 56,00 \\
2 - Custo Variável por hectare & $1.057,23$ & $1.390,28$ & $1.187,54$ \\
3 - Custos Fixos por hectare & 145,85 & 177,51 & 180,83 \\
3 - Receita de Venda & 27,50 & 37,50 & 27,50 \\
4 - ( - ) Custos Variáveis por saca & 19,58 & 24,39 & 21,21 \\
5 - Margem de Contribuição por saca = 3-4 & 7,92 & 13,11 & 6,29 \\
6 - ( - ) Custos Fixos por saca & 2,70 & 3,11 & 3,23 \\
7 - Lucro Líquido p/ saca = 5-6 & 5,22 & 9,99 & 3,06 \\
\hline
\end{tabular}

O ponto de equilíbrio representa a quantidade de unidades que a empresa precisa produzir para custear seus custos de produção. No demonstrativo referente às safras de 2007/2008, 2008/2009 e 2009/2010, se observa que no ano safra 2007/2008 a propriedade Santa Rita precisava produzir 19,41 sacas por hectare para custear sua produção, na safra 2008/2009, devido a alta dos preços de venda, a propriedade necessitou de uma quantidade menor, ou seja, de 15,37 sacas por hectare. Na safra 2009/2010 a quantidade necessária de produção para cobrir seus custos foi de 38,01 sacas por hectares (Tabela 7).

Tabela 7- Ponto de Equilíbrio referente Safra 2007/2008, Safra 2008/2009 e Safra 2009/2010 da Fazenda Santa Rita

\begin{tabular}{llll}
\hline Fazenda Santa Rita & SAFRA & SAFRA & SAFRA \\
& $2007 / 2008$ & $2008 / 2009$ & $2009 / 2010$ \\
\hline 1 - Custos Fixos por hectare & 154,17 & 201,98 & 177,04 \\
2 - Margem de Contribuição p/sc & 7,94 & 13,14 & 4,66 \\
PONTO DE EQUILIBRIO "EM SACAS" = 1/2 & 19,41 & 15,37 & 38,01 \\
\hline
\end{tabular}

Observa-se que no ano safra 2007/2008 a propriedade AGL precisou produzir 18,41 sacas por hectares para custear sua produção. Novamente, devido ao aumento de preços na safra 208/2009 houve a necessidade de produzir 13,54 sacas por hectare, 
terminando no último período com uma quantidade de produção maior, de 28,73 sacas por hectare (Tabela 8).

Tabela 8 - Ponto de Equilíbrio referente Safra 2007/2008, Safra 2008/2009 e Safra 2009/2010 da Fazenda AGL

\begin{tabular}{llll}
\hline Fazenda AGL & SAFRA & SAFRA & SAFRA \\
& $2007 / 2008$ & $2008 / 2009$ & $2009 / 2010$ \\
\hline 1 - Custos Fixos por hectare & 145,85 & 177,51 & 180,83 \\
2 - Margem de Contribuição por saca & 7,92 & 13,11 & 6,29 \\
PONTO DE EQUILIBRIO "EM SACAS" = 1/2 & 18,41 & 13,54 & 28,73 \\
\hline
\end{tabular}

Comparando o ponto de equilíbrio da fazenda Santa Rita com a Fazenda AGL observa-se que a produtividade das fazendas foi determinante para a diferença deste índice. Mesmo com os custos de produção por hectare superiores, a AGL tem maior margem de quantidade de sacas necessárias para custear sua produção, devido a maior produtividade (Tabelas 7 e 8 ).

$\mathrm{Na}$ demonstração da margem de segurança operacional, a propriedade Santa Rita apresentou alterações entre os períodos. Na safra 2007/2008 a margem de segurança foi de 21,59 sacas por hectare produzido, superior em $111 \%$ ao ponto de equilíbrio. Para o período safra 2008/2009 novamente a margem foi superior, equivalendo-se $160 \%$ maior que o ponto de equilíbrio, justificada pela alta de preços de mercado. Já na safra 2009/2010 a margem de segurança caiu significativamente com $6,55 \%$, justificado por uma queda nos preços de mercado (Tabela 9 ).

Tabela 9- Margem de Segurança Operacional referente Safra 2007/2008; Safra 2008/2009 e Safra 2009/2010 da Fazenda Santa Rita

\begin{tabular}{llll}
\hline & Safra 2007/2008 & Safra 2008/2009 & Safra 2009/2010 \\
1- Volume Unidades Produzidas He (Sacas) & 41,00 & 40,00 & 40,50 \\
2- Quantidade no Ponto de Equilíbrio (Sacas) & 19,41 & 15,37 & 38,01 \\
MSO. (Sacas) $=1-2$ & 21,59 & 24,63 & 2,49 \\
\hline
\end{tabular}


$\mathrm{Na}$ margem de segurança operacional da propriedade AGL, observa-se assim como na propriedade Santa Rita, alterações expressivas entre os períodos analisados. Em 2007/2008 a margem de segurança foi de 35,59 sacas por hectare, ou seja, evidenciando margem de segurança de $103,32 \%$ superior em relação ao ponto de equilíbrio. No período seguinte a margem foi ainda maior, equivalendo a $321 \%$ em relação ao ponto de equilíbrio, justificada, como já comentado, pela alta nos preços de mercado. Por fim, na safra 2009/2010 a margem de segurança em comparação com os períodos anteriores apresentou redução, situando-se em 94,92\% superior em relação ao ponto de equilíbrio, devendo-se principalmente a oscilação na redução dos preços de mercado (Tabela 10).

Tabela 10- Margem de Segurança Operacional referente Safra 2007/2008; Safra 2008/2009 e Safra 2009/2010 da Fazenda AGL

\begin{tabular}{llll}
\hline & Safra 2007/2008 & Safra 2008/2009 & Safra 2009/2010 \\
\hline 1 - Volume Unidades Produzidas He (Sacas) & 54,00 & 57,00 & 56,00 \\
2- Quantidade no Ponto de Equilíbrio (Sacas) & 18,41 & 13,54 & 28,73 \\
MSO. (Sacas) $=1$-2 & 35,59 & 43,46 & 27,27 \\
\hline
\end{tabular}

Comparando os índices da fazenda AGL com a Fazenda Santa Rita, verifica-se uma diferença considerável na margem de segurança, onde na primeira safra a propriedade AGL obteve uma margem de segurança de aproximadamente 64,84\% superior a de Santa Rita. Na segunda safra a margem de segurança da fazenda AGL foi superior em $76,45 \%$ em relação a Santa Rita. Por fim, na terceira safra a propriedade AGL obteve margem de segurança de 995,18\% superior a de Santa Rita. As diferenças são justificadas pela produtividade das duas propriedades em todos os períodos analisados. Na safra 2009/2010 a propriedade Santa Rita não obteve margem de contribuição confortável, pois o ponto de equilíbrio comparado a safra 2007/2008 teve elevação de aproximadamente $56,06 \%$, não havendo alteração na receita (Tabelas 9 e 10). 
Estudo sobre a rentabilidade da cultura da soja em propriedades rurais de Diamantino/MT

Cleiton Franco, André da Silva Matheus, Karine Medeiros Anunciatto, Talitha Soyara Zanini

Tabela 11- Grau de Alavancagem Operacional referente Safra 2007/2008; Safra 2008/2009 e Safra 2009/2010 da Fazenda Santa Rita

\begin{tabular}{lccc}
\hline & Safra 2007/2008 & Safra 2008/2009 & Safra 2009/2010 \\
\hline 1 Produtividade por He & 41,00 sacas & 40,00 sacas & 40,50 sacas \\
2 Receita por He & $1.127,50$ & $1.500,00$ & $1.113,75$ \\
3 (-) Custos e despesas variáveis & 801,78 & 974,40 & 925,11 \\
4 (=) Margem de Contribuição & 325,72 & 525,60 & 188,64 \\
5 (-) Custos e despesas fixos & 154,17 & 201,98 & 177,04 \\
6 (=) Lucro Operacional & 171,55 & 323,62 & 11,60 \\
7 Variação Percentual da Receita & 0,00 & $(+) 33,04 \%$ & $(-) 1,22 \%$ \\
8 Variação percentual do Lucro & 0,00 & $(+) 88,64 \%$ & $(-) 93,24 \%$ \\
& & & \\
\hline 9 Grau de Alavancagem Operacional = 8/7 & 0,00 & 2,68 & $-76,43$ \\
\end{tabular}

Quanto ao grau de alavancagem operacional da fazenda Santa Rita, analisando e comparando os três períodos, os resultados apresentados apontam que na safra 2008/2009 o grau de alavancagem operacional apresentou-se em 2,68, ou seja, o lucro operacional aumentou 2,68 vezes na relação com a safra anterior, resultado influenciado pelo aumento das receitas que se elevaram 33,04\%, proporcionando um lucro de $88,64 \%$ superior a safra anterior. Na safra 2009/2010 o grau de alavancagem operacional apresentou redução de 76,43 vezes comparada a relação na safra $2007 / 2008$, justificada pela baixa nas receitas que reduziram em $1,22 \%$, suficiente para provocar uma queda de 93,24\% no lucro referente a safra 2007/2008 (Tabela 11). 
Tabela 12- Grau de Alavancagem Operacional referente Safra 2007/2008; Safra 2008/2009 e Safra 2009/2010 da Fazenda AGL

\begin{tabular}{llcc}
\hline & Safra 2007/2008 & Safra 2008/2009 & Safra 2009/2010 \\
\hline 1 Produtividade por He & 54,00 sacas & 57,00 sacas & 56 sacas \\
2 Receita por He & $1.485,00$ & $2.137,50$ & $1.540,00$ \\
3 (-) Custos e despesas variáveis & $1.057,23$ & $1.390,28$ & $1.187,54$ \\
4 (=) Margem de Contribuição & 427,77 & 747,22 & 352,46 \\
$5(-)$ Custos e despesas fixos & 145,85 & 177,51 & 180,83 \\
6 (=) Lucro Operacional & 281,92 & 569,71 & 171,63 \\
7 Variação Percentual da Receita & 0,00 & $(+) 43,94 \%$ & $(+) 3,704 \%$ \\
8 Variação percentual do Lucro & 0,00 & $(+) 102,08 \%$ & $(-) 39,12 \%$ \\
9 Grau de Alavancagem Operacional = 8/7 & & & $-10,56$ \\
\end{tabular}

No demonstrativo do grau de alavancagem operacional da fazenda AGL, tendo como base de análise a primeira safra, tem-se que no período seguinte o lucro operacional aumentou 2,23 vezes em relação a safra anterior, resultado influenciado pelo aumento das receitas decorrentes da elevação dos preços de mercado. Na safra 2009/2010 a fazenda obteve um grau de alavancagem operacional reduzido, apresentando-se negativamente em 10,56 vezes em relação a safra 2007/2008 (Tabela 12).

Comparando com os índices da fazenda Santa Rita, observa-se que o grau de alavancagem operacional das propriedades na safra 2008/2009 não apresentou diferenças significativas, porém a fazenda AGL apresenta alavancagem de aproximadamente $20,18 \%$ inferior a da Fazenda Santa Rita. Na safra 2009/2010 as duas propriedades apresentam índices negativos, devido à baixa no lucro operacional, proporcionado pela elevação dos custos fixos e variáveis e estabilidade com os preços do período safra 2007/2008. 
Estudo sobre a rentabilidade da cultura da soja em propriedades rurais de Diamantino/MT

Cleiton Franco, André da Silva Matheus, Karine Medeiros Anunciatto, Talitha Soyara Zanini

\section{CONSIDERAÇÕES FINAIS}

O conhecimento dos custos de produção é relevante para o eficaz controle da propriedade rural. O produtor/empresário precisa dispor de sistema de controle de custos confiável para o planejamento das safras seguintes, por isso o controle das informações permite que o produtor conheça a real condição financeira, econômica e produtiva de sua propriedade, garantindo assim uma tomada de decisão eficiente e objetiva na hora de decidir o que plantar, quanto, quando, quantidade de recursos necessários, bem como o tipo de tecnologia a ser utilizada.

Para responder objetivamente a estas questões, o produtor precisa de informações contendo o máximo de confiabilidade possível, contando com um correto controle de custos que possa transmitir as informações necessárias para a tomada de decisão. Nesse sentido, observa-se nos relatórios apresentados pela fazenda Santa Rita uma deficiência na distribuição dos recursos em seu processo de produção, influenciando no resultado produtivo. Na fazenda AGL, por sua vez, houve uma maior preocupação na distribuição dos recursos, obtendo maior produtividade e rentabilidade.

No decorrer do estudo observou-se que os custos variáveis não representam os maiores custos da produção, uma vez que se aplicados de forma correta e controlada proporcionam maior produtividade e rentabilidade. Nesta hipótese é valido é afirmar que sem controles destes custos a fazenda não consegue obter resultados satisfatórios, cabendo ressaltar que o controle dos custos fixos também influencia no resultado operacional, evidenciando de forma clara a real situação.

Foram identificados, também, os fatores que influenciam no resultado da produção, como preços dos insumos, diferença nas distribuições dos custos fixos e variáveis, preços de mercado e outros fatores de relevância que influenciaram no resultado operacional de cada uma das fazendas analisadas.

Ficou evidenciado também que a oscilação de preços de mercado afeta os resultados e consequentemente a rentabilidade das empresas. Assim, não basta a eficiência em produtividade, pois há a necessidade de melhor acompanhamento das 
relações mercadológicas, bem como informações de produção de outros países como Estados Unidos e Argentina que afetam diretamente a produção no Brasil, principalmente em Mato Grosso, estado com maior participação percentual da produção nacional.

\section{REFERÊNCIAS}

APROSOJA, Associação dos Produtores de Soja do Estado de Mato Grosso. Levantamento de safra - MT. Disponível em: <http://www.aprosoja.com.br/novosite/estatisticav.php?cate=1>. Acesso em: 25/out/ 2010.

ANDRADE, M.G.F. DE; MORAIS, M.I. DE; MUNHÃO, E.E; PIMENTA, P.R. (2012). Controle de custos na agricultura: um estudo sobre a rentabilidade na cultura da soja. Custos e agronegócio online, Recife, volume 8, número 3, p. 1-173, Julho/Setembro.

ATKINSON, Anthony A.; BANKER, Rajiv D.; KAPLAN, Robert S.; YOUNG, Mark. (1997). Contabilidade gerencial. São Paulo: Atlas, 2000. Tradução de Management Accounting, (2 ed.). Englewood Cliffs, Prentice Hall.

BRAGA, Roberto. (1995). Fundamentos e técnicas de administração financeira. São Paulo: Atlas.

BRUNI, A.L.; FAMÁ, R. (2004). Gestão de Custos e Formação de Preços: com aplicações na calculadora HP $12 C$ e Excel. (3 ed.). São Paulo: Atlas.

CELESTINO, João Garibaldi Almeida Viana Vicente; SILVEIRA, Pires. (2009). Análise econômica da ovinocultura: estudo de caso na Metade Sul do Rio Grande do Sul, Brasil. Ciência Rural, v. 39, n. 4, p. 1187-1192.

EYERKAUFER, Marino Luiz; COSTA Adilson; FARIA, Ana Cristina de. (2007). Métodos de custeio por absorção e variável na ovinocultura de corte: estudo de caso em uma cabanha. Organizações Rurais \& Agroindustriais, Lavras, v. 9, n. 2, p. 202-215.

FRANCO, Cleiton. (2009). Análise das transações e estruturas de governança na cadeia produtiva da avicultura de corte em Mato Grosso. (Dissertação de mestrado). UFMT. Cuiabá.

FRANCO, C., EIDT, K. M., ANUNCIATO, K. M., MELZ, L. J., \& DE ANDRADE, M. G. F. (2011). Soja convencional versus soja transgênica: análise comparativa de custos de 
produção e rentabilidade na fazenda missioneira, campo novo do parecis-mt. Revista de Estudos Sociais, v. 13, n. 25.

IMEA, Instituto Matogrossense de Economia Agropecuária. Estatísticas. Disponível em: <http://www.imea.com.br/index.php> Acesso em: 24/mar/2009.

GARRISON, Ray H.; NOREEN, Eric W.; BREWER, Peter C. (2007). Contabilidade Gerencial. (11 ed.). Rio de Janeiro: LTC.

GIL, A. C. (2003). Técnicas de pesquisa em economia e elaboração de monografias. (4 ed.). São Paulo: Atlas.

HANSEN, Don R.; MOWEN, Maryanne M. (2000). Gestão de custos: contabilidade e controle. São Paulo: Pioneira Thomson Learning, 2001. Tradução de Cost management: accounting and control, South-Western College Publishing.

HORNGREN, Charles T.; SUNDEM, Gary L.; STRATTON, William O. (2004). Contabilidade gerencial. Prentice Hall.

LEONE. G.G. (1997). Curso de Contabilidade de Custos. São Paulo: Atlas.

KOLIVER, Olivio. (2003). A Contabilidade e os Contadores a Serviço do Judiciário. Porto Alegre: CRCRS.

MALAVAZI, DE SOUZA, A.; FUGITA, D. E. (2006). Custeio variável como um instrumento de gestão para as empresas rurais. Anais 2006 da Semana de Ciências Contábeis da Universidade Estadual de Maringá (UEM), Maringá.

MARION, José Carlos. (2002). Contabilidade Rural: Contabilidade Agrícola, Contabilidade da Pecuária da Pecuária, Imposto de Renda, Pessoa Jurídica. (4 ed.). São Paulo: Atlas.

MARTINS, Eliseu. (2001). Contabilidade de Custos. Inclui o ABC. (8 ed.). São Paulo: Editora Atlas.

MEGLIORINI, E. (2007). Custos: análise e gestão. (2 ed.). São Paulo: Pearson Prentice Hall.

MENEGATTI, A. L. A. BARROS, A. L. M. (2007). Análise comparativa dos custos de produção entre soja transgênica e convencional: um estudo de caso para o Estado do Mato Grosso do Sul. Revista de Economia e Sociologia Rural, v. 45, n. 1, p. 163-183. 
PADOVEZE, Clóvis Luís. (2000). Contabilidade Gerencial: um enfoque em sistema de informação contábil, (3 ed.). São Paulo: Atlas.

SILVA, Andréa Lago da; ONOYAMA, Márcia Mitiko. (2008). Competitiveness of Poultry Agrisystem. Relatório de pesquisa, São Carlos.

YIN, Robert K. (2001). Estudo de caso: planejamento e métodos. (2 ed.). Porto Alegre: Bookmann.

Data de Submissão: 26/04/2013

Data de Aceite: 18/02/2014 